\title{
In reply: Substance use disorder in Canadian university departments of anesthesia
}

\author{
Purva Kristina Khanduja, MBChB $\cdot$ Sherif Boulis, MD - Kirsti Downey, MSc • \\ Zeev Friedman, MD
}

Received: 4 November 2015/Accepted: 9 November 2015/Published online: 8 December 2015

(C) Canadian Anesthesiologists' Society 2015

\section{To the Editor,}

We are grateful for the comments and interesting points raised by Dr. Craig ${ }^{1}$ in reference to our recent paper on substance abuse disorders in Canadian anesthesia departments. $^{2}$

We purposely surveyed hospital site chiefs and residency program directors as our target responders. Although our decision resulted in a smaller overall survey size, our respondents were best positioned to represent our group of interest whilst avoiding duplicate reports of individuals affected by alcohol and substance abuse. Unfortunately, our study did suffer from a low response rate; at $48 \%$, it does introduce a risk of nonresponse bias. The estimated incidence of alcohol and substance abuse amongst both trainees and attending anesthesiologists at academic centres thus forms a modest attempt at determining the true scope of the problem in anesthesiology.

In our discussion, we draw comparisons with previously published surveys of substance abuse amongst anesthesia trainees and faculty. Although Dr. Craig refers to the report published by Warner et al. in $2013^{3}$ - work that forms a valuable contribution to the issue of substance abuse amongst anesthesia residents in North Americasignificant differences in methodology do not allow for a direct comparison with our findings. The aforementioned report $^{3}$ does, however, bring two important points to the surface that we have raised in our paper and would like to re-emphasize. Firstly, the report highlights that such regulatory bodies as the American Board of Anesthesiology in North America can take ownership of substance abuse and its related problems through mandatory anonymous reporting of confirmed cases. Secondly, it forms an excellent example of the impact that formal data collection can have on furthering our understanding of the epidemiology of substance abuse amongst anesthesiologists.

We agree with Dr. Craig that improvement in the reporting of both substance abuse cases and physician outcomes can be achieved only through concerted efforts from all stakeholders, both within and outside the specialty of anesthesiology.

Conflicts of interest None declared.

\section{References}

1. Craig D. Substance use disorder in Canadian university departments of anesthesia. Can J Anesth 2016; 63: this issue: DOI: $10.1007 / \mathrm{s} 12630-015-0533-6$.

2. Boulis $S$, Khanduja PK, Downey K, Friedman Z. Substance abuse: a national survey of Canadian residency program directors and site chiefs at university-affiliated anesthesia departments. Can J Anesth 2015; 62: 964-71.

3. Warner DO, Berge K, Sun H, Harman A, Hanson A, Schroeder $D R$. Substance use disorder among anesthesiology residents, 19752009. JAMA 2013; 310: 2289-96.

P. K. Khanduja, MBChB ( $₫) \cdot$ S. Boulis, MD .

K. Downey, MSc $\cdot$ Z. Friedman, MD

Department of Anesthesia and Pain Management, Mount Sinai

Hospital, University of Toronto, Toronto, ON, Canada

e-mail: KKhanduja@mtsinai.on.ca 